\title{
Using the GENESYS model quantifying the effect of cropping systems on gene escape from GM rape varieties to evaluate and design cropping systems
}

Oléagineux, Corps Gras, Lipides. Volume 11, Numéro 1, 11-20, JANVIER/FÉVRIER 2004, OGM

\author{
Author(s) : Nathalie COLBACH ${ }^{1}$, Frédérique ANGEVIN², Jean-Marc MEYNARD ${ }^{3}$, Antoine MESSÉAN ${ }^{2,4}$ \\ ${ }^{1}$ UMR Biologie et Gestion des Adventices, INRA, BP 86510, 17 rue Sully, 21065 DIJON Cedex, France \\ $<$ Nathalie.Colbach@dijon.inra.fr> \\ 2 INRA Eco-Innov, BP 01, 78850 Thiverval-Grignon, France. \\ $<$ frederique.angevin@jouy.inra.fr> \\ ${ }^{3}$ UMR d'Agronomie, INRA INA P-G, BP 01, 78850 Thiverval-Grignon, France. \\ $<$ meynard@grignon.inra.fr> \\ ${ }^{4}$ Cetiom, Centre de Grignon, BP 4, 78850 Thiverval-Grignon, France. \\ $<$ messean@cetiom.fr >
}

Summary : Gene flow in rapeseed is a process taking place both in space and over the years and cannot be studied exclusively by field trials. Consequently, the GENESYS model was developed to quantify the effects of cropping systems on transgene escape from rapeseed crops to rapeseed volunteers in neighbour plots and in the subsequent crops. In the present work, this model was used to evaluate the risk of rape harvest contamination by extraneous genes in various farming systems in case of co-existing GM, conventional and organic crops. When $50 \%$ of the rape varieties in the region were transgenic, the rate of GM seeds in non-GM crop harvests on farms with large fields was lower than the $0.9 \%$ purity threshold proposed by the EC for rape crop production (food and feed) harvests, but on farms with smaller fields, the threshold was exceeded. Harvest impurity increased in organic farms, mainly because of their small field size. The model was then used to evaluate the consequences of changes in farming practices and to identify those changes reducing harvest contamination. The effects of these changes depended on the field pattern and farming system. The most efficient practices in limiting harvest impurity comprised improved set-aside management by sowing a cover crop in spring on all set-aside fields in the region, permanently banning rape crops and set-aside around seed production fields and (for non-GM farmers) clustering farm fields to reduce gene inflow from neighbour fields.

Keywords : model, cropping system, gene flow, oilseed rape GM crops, coexistence

\section{ARTICLE}

Gene flow in rapeseed is a process taking place both in space and over the years. Pollen is dispersed by wind and insects over large distances and is mainly responsible for gene exchanges between neighbour fields. Rape seeds lost before and during harvest can survive for several years and give rise to volunteers in the subsequent crops which are then responsible for gene flow over time. 
Furthermore, all these processes strongly interact with the regional cropping system. In order to forecast the spread and behaviour of transgenes and their impacts in a wide range of situations, modelling is a key element as it is impossible to evaluate gene flow solely with field experiments. Consequently, the GENESYS model [1-3] was developed by INRA, in collaboration with Cetiom, to quantify the effects of cropping systems on transgene escape from rapeseed crops to rapeseed volunteers in neighbour fields and uncultivated areas, and in the subsequent crops. The aim of this model is to evaluate the influence of cropping systems (regional crop distribution, crop succession, cultivation techniques), in order to determine those cropping systems with a high dispersal risk, to design new cropping systems that limit gene flow, to evaluate the effect of changing practices and to identify rapeseed cultivar characteristics increasing/decreasing risk of gene flow.

Before introducing and growing GM crops in Europe, it is necessary to determine rules for labelling and traceability of GMOs [4]. In July 2003, the European Commission edited recommendations for elaborating national strategies and optimal practices to make the coexistence between GM and nonGM crops possible [5]. These guidelines must be based on scientific data and continuously updated, using results from assessments after the commercialisation of the GM crops as well as from simulation models validated with field data. The present paper shows how the GENESYS model can be used to test and choose farming practices in order to respect harvest purity thresholds in the case of co-existing GM, conventional and organic crops in a large range of agricultural situations and farming systems. The paper did not aim at concluding on how to grow GM rape.

\section{Material and methods}

\section{Model presentation}

The detailed structure of the GENESYS model is presented by Colbach et al. [1-3]. Only the main aspects will be described here.

The input variables of the model are the regional field pattern comprising uncultivated road and field margins (hence "borders"), the succession of crops of each field, the management of each crop defined by a series of cultural techniques and rapeseed variety characteristics. The main output variables are, for each year, the adult rapeseed plants, the newly produced seeds and the seed bank ; for each of these variables, both the number of individuals and the genotypic proportions of these individuals are given.

The model comprises an annual life-cycle for the rapeseed plants, whether volunteer or cropped plants, that is simulated for each plot and year. The life-cycle comprises seed bank, seedlings, adults, flowers, imported and exported pollen, seed production, imported and exported seed. For each stage, the number of individuals and the proportions of the different genotypes are calculated. The relationship between the temporal compartments depends on crop type and management. Pollen and seed exchanges between plots depend on plot areas, shapes and distances as well as on rape flowering dates.

\section{Model evaluation}

Before using a model, it is necessary to evaluate the model. The first step was to check whether variations in input variables indeed produced the expected variations in simulated output. Then, the sensitivity of the model to its input variables and parameters was analysed. This analysis identified 
the major input variables to be collected during the field surveys in order to obtain satisfactory simulations [6]. It is also necessary to compare simulations carried out with the model to independent observations in order to determine the domain of validity in which the model can be used and which precautions are necessary when using the model [7]. In this step, four small regions were chosen and their cropping history recorded for each field and border. The first region comprised farmers' fields with a large proportion of conventional rape varieties and in 1998 all rape volunteers of the region were counted. The three remaining regions comprised the field experiments set up by INRA and the French technical institutes for evaluating the management and performance of transgenic rape, sugar beet and maize varieties [8, 9]. From 1996 onwards, numbers and herbicide tolerance of rape volunteers after crop harvests were estimated. Furthermore, the proportions of transgenic seeds in the rape harvest were also assessed. The comparison of simulated and observed variables showed that globally the model correctly ranks the fields according to their volunteer infestation (Kendall correlation 0.44 ) and predicts volunteer densities accurately (modeling efficiency 0.93), except in spring crops where infestations were frequently underestimated. Post-harvest volunteer densities and genotypes as well as rape harvest genotypes were also correctly predicted (ex of Dijon location $r^{2}=0.84,0.67$ and 0.77 , respectively). However, the model systematically underestimates gene flow in space and the actual observed dispersal distance was approximately double the simulated dispersal distance.

When using the current version of GENESYS for simulations and advice, the user must therefore keep in mind a few precautions: gene flow is probably underestimated after rotations with frequent spring crops. Furthermore, when plotting harvest contamination or any other genotypic output variable as a function of dispersal distance, the user should correct the distance axis by doubling all simulated distances to correct for the spatial underestimation observed during model evaluation. When comparing harvest contamination in different cropping systems, the margin of error to consider is approximately half an order of magnitude which was the mean observed error during model evaluation.

\section{Simulations}

Several aspects were analysed in the present paper :

- how to determine isolation distance between two different rape varieties to respect harvest purity thresholds, in interaction with regional crop succession and volunteer management,

- how to evaluate harvest purity in existing farming systems and thus to identify the main factors responsible for gene flow between co-existing rape varieties,

- how to determine changes in agricultural practices that contribute to limit harvest contamination, in different regional field patterns and farming systems.

In the first part, a schematic field pattern was designed where the isolation distance between the coexisting rape varieties could easily be made to vary from nil to large distances, with all intermediate situations. The simulated cropping system was one usually found in conventional farms and only its two main aspects, i.e. the frequency of GM varieties and rape volunteer management in borders and set-aside, were made to vary between extremes to analyse their interaction with isolation distance. The second part was based on field patterns and cropping systems chosen to be representative of 
various French and European regions, ranging from small-field farms in South-Western France to large-field farms in Central France. They comprise both conventional (intensive) and organic farms, growing food and feed rape and, in some cases, rape for certified hybrid seed production. These simulations were carried out during a study for JRC-IPTS [10]. In the last part, all aspects of the farming system were made to vary in each of the previously studied farms to analyse their effects on harvest contamination. These changes ranged from those easy to achieve (e.g. change sowing dates) to costly ones (e.g. sow set-aside fields); some only concerned the farmers, others also his neighbours (e.g. permanently ban rape crops and set-aside around non-GM fields); most only concerned cultivation techniques, others the regional field pattern (e.g. cluster farm fields). In all simulations, the introduced GM variety was glyphosate tolerant and homozygous for the transgene ("AA"). Pollen and yield potential of the GM variety was equal to that of non-GM varieties. All varieties presented a self-pollination rate of $70 \%$, except the male-sterile plants used in hybrid seed production which were all allogameous because they did not produce any pollen. After the simulations were run, the harvest contamination, i.e. the proportion of GM seeds in nonGM harvests, of each simulation corresponding for instance to a given isolation distance, farm or change in cultivation practices, was analysed, relative to the initial situation (e.g. existing farming system) and relative to harvest purity thresholds. The observed rankings of cultivation practices and, even more, the simulated harvest impurity rates cannot be extrapolated from the present simulated farms to other situations.

\section{Results}

\section{Using the model to determine isolation distances between different varieties}

Figure 1 shows an example of isolation distance between a non-GM rape variety and a homozygous GM herbicide tolerant variety in a region cultivating otherwise only non-GM crops. In the study, isolation distance was made to vary from $0 \mathrm{~m}$, where the GM and non-GM varieties were adjacent, to $600 \mathrm{~m}$. All fields were grown with a rape/winter wheat/spring barley rotation and a set-aside before the rapeseed every 7 years. The only exception was the analysed non-GM field where rape was only grown every 7 years. Cropping systems were intensive, with herbicide use in all crops; borders and set-aside were cut when rape volunteers started to flower. The proportion of GM seeds in the nonGM harvest was high for adjacent fields (approx. $3 \%$ ) and decreased with the isolation distance between the two varieties (figure 2). However, the harvest contamination increased considerably with the impurity rate, i.e. the rate of GM seeds, of the seed lots used to sow the non-GM crops. Regardless of this, in order to ensure a GM content of less than $0.9 \%$ (i.e. the threshold proposed by the European Union for non-GM rape crop production, [11]), an isolation distance of approximately $200 \mathrm{~m}$ was necessary in the present field pattern.

The previous simulation was carried out in a region exclusively cultivated with non-GM varieties except for the single source GM variety. If now the region were mainly cultivated with $G M$ varieties, the situation would be very different (figure 3). Indeed, in case of non-optimal volunteer management in set-aside and borders (early cutting), isolation distance only made harvest contamination decrease in the year when the GM varieties were introduced into the region. With increasing time, the GM volunteers then spread in the region and after several years, isolation distance between the varieties became totally inefficient. If however, a stringent volunteer management was applied, with double or late cutting of all borders and set-aside fields to suppress 
any volunteer seed production, then isolation distance made the harvest impurity rate decrease again. The necessary distance to keep harvest contamination below the $0.9 \%$ threshold was again approximately $200 \mathrm{~m}$. When studying isolation distance for ensuring harvest purity in case of seed production, the type of produced seeds was very important (figure 4). Impurity rates of hybrid seed production were always higher than those for conventional seeds. Indeed, the male-sterile plants used in hybrid seed production are much more sensitive to extraneous (GM) pollen import than male-fertile plants diluting the external pollen by their own (GM-free) pollen. When the seeds were produced in a region with only one GM field, isolation distance was again $200 \mathrm{~m}$, regardless of seed type. If however the seed production field was the only non-GM field, impurity rates increased tremendously. Isolation distance for conventional seeds had to be doubled to $400 \mathrm{~m}$ to decrease impurity rates below the $0.3 \%$ threshold [11], whereas this threshold was always exceeded for hybrid seeds. The sudden increase in impurity rates observed for the simulated isolation distance of $400 \mathrm{~m}$ in the GM region was due to a set-aside field adjacent to the seed production field, a combination that never occurred in the other simulations. Volunteer management in set-aside was optimised to avoid seed set of volunteers and could not avoid pollen production and therefore gene flow to the seed production field.

\section{Evaluating existing farming systems}

In 2001, GENESYS was used during a study for the Joint Research Center/European Commission to evaluate the consequences of coexisting GM, non-GM and organic crops. Details are given by Angevin et al. [10]. Three organic farms and two conventional farms were simulated, using small (1 ha - farm OS), medium (5-6 ha - farms OM and IM) or very large fields ( 13 ha - farms OL and IL) and always surrounded by conventional farms. The farm fields were scattered in the simulated region (figure 5). Simulated differences in cropping systems (table 1) between intensive and organic farms mainly concerned crop rotations (more spring crops on organic farms), tillage (more ploughing) and weed management (mechanical instead of chemical). The large-field farms IL and OL used farmsaved seeds instead of certified seeds. Three of the farms produced non-GM hybrid seeds every 6 years (farms IM, OM and OS). During the year of seed production, isolation distance, i.e. distance to the nearest rape crop, was $200 \mathrm{~m}$ for the hybrid seed production field. There was no isolation distance for rape crop production. Regional crop rotations comprised $10-12 \%$ of oilseed rape. The analysed farms did not grow GM crops, but their neighbour cultivated $50 \%$ of the rape area with GM varieties.

Table 1 Cropping systems of intensive and organic farms in the simulated regions.

A. Field plan and rotation.

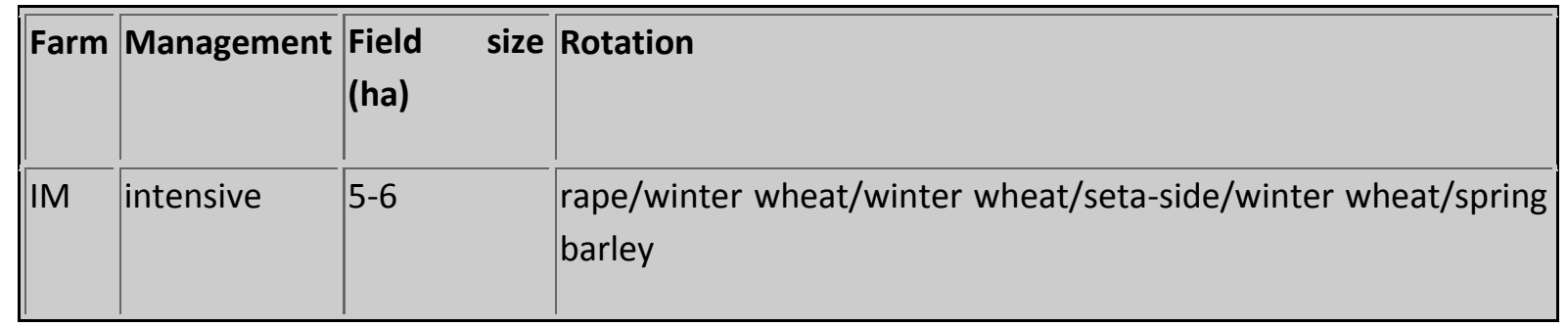




\begin{tabular}{|l|l|l|l|l|}
\hline OM & organic & $5-6$ & $\begin{array}{l}\text { rape/winter wheat/spring barley/seta-side/winter wheat/spring } \\
\text { barley }\end{array}$ \\
\hline OS & organic & 1 & $\begin{array}{l}\text { rape/winter wheat/spring barley/seta-side/winter wheat/spring } \\
\text { barley }\end{array}$ \\
\hline IL & intensive & 13 & rape/winter wheat/winter wheat \\
\hline OL & organic & 13 & $\begin{array}{l}\text { rape/winter wheat/spring barley/seta-side/winter wheat/spring } \\
\text { barley }\end{array}$ \\
\hline
\end{tabular}

B. Crop management.

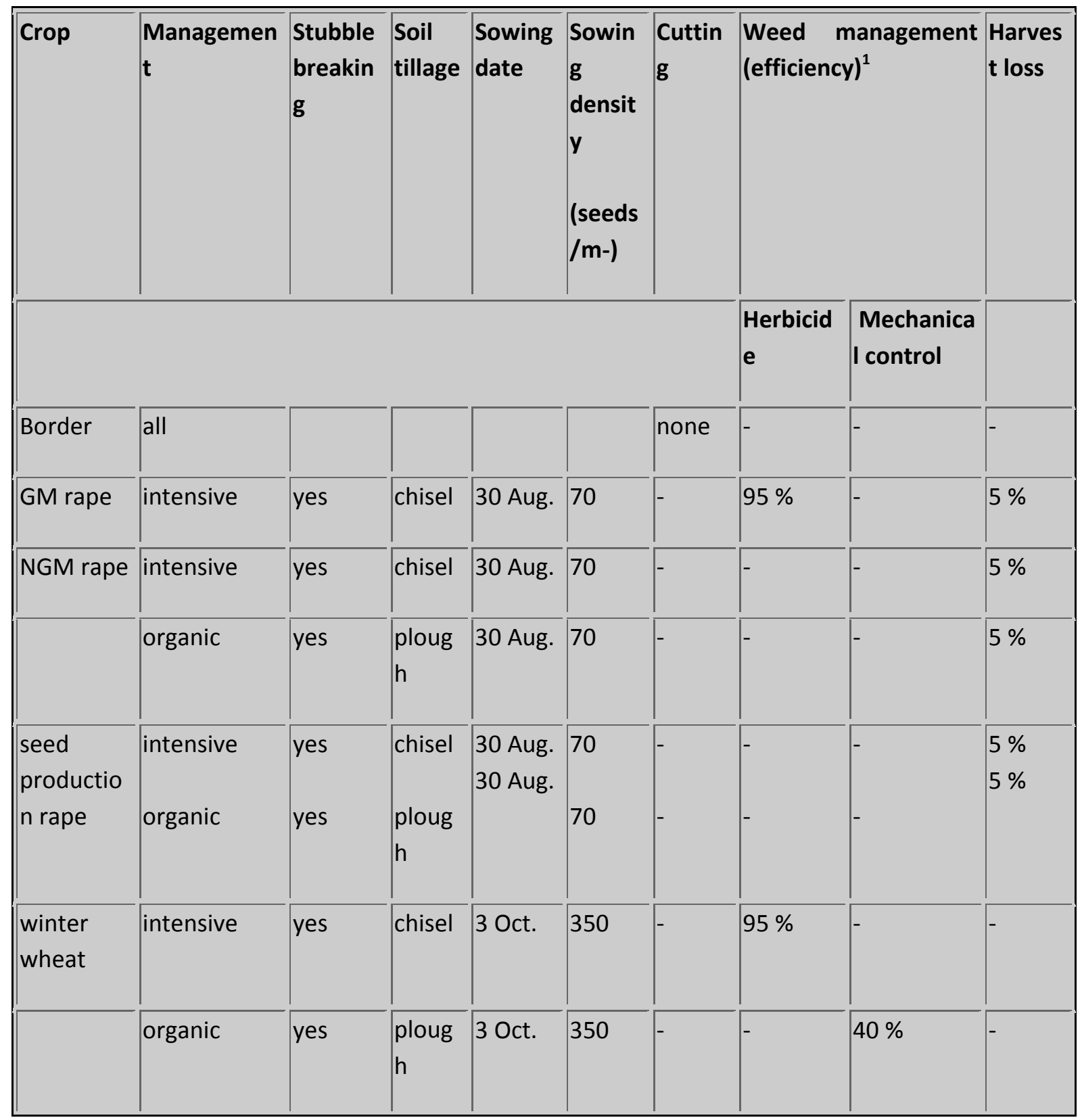




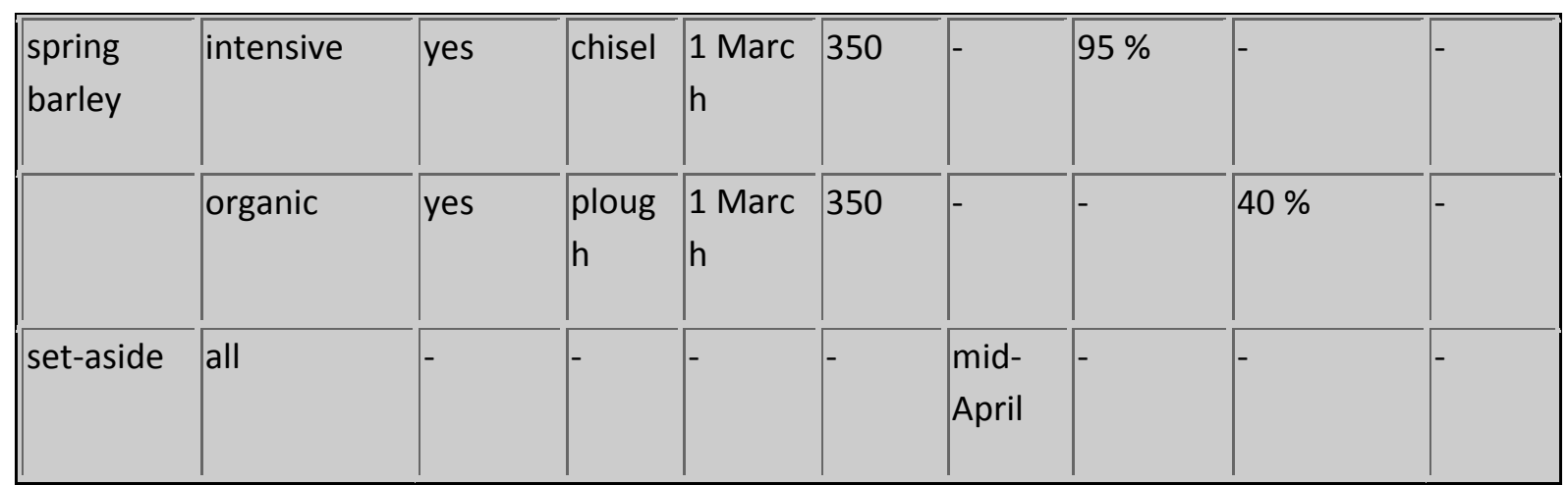

${ }^{1}$ Herbicide efficiencies were based on Mamarot and Rodriguez [17]. Mechanical weed control efficiencies were based field assessments in a network of organic farms.

In these conditions, the simulated harvest contamination usually exceeded the maximum acceptable rate of GM seeds in non-GM harvests, i.e. $0.9 \%$ for crop and $0.3 \%$ for seed production (figure 6). Impurity rates varied greatly among years and fields for crop production. Depending on the nature of the neighbour fields, harvest pollution could either increase (e.g. neighbour set-aside with numerous volunteers) or decrease enormously (e.g. spring crops with little volunteers). Organic farm management slightly increased harvest contamination of both crop and seed production (OM vs. IM farm) because of the lower efficiency of weed and volunteer management. However, the main factor was field size. Farms with large fields (OL and IL) presented the lowest harvest pollution, irrespective of cropping system, because the larger the rape field, the more pollen it produces and the less sensitive it is to extraneous pollen import. However, French organic farms often have very small fields such as the OS farm, and are thus very exposed to pollen import and harvest contamination.

\section{Effects of changes in the cropping system of intensive farm IM}

For each farm were then simulated a series of changes in the cropping practices in order to identify those techniques minimising harvest impurity rates. The GM content of the hybrid seed production and crop production harvests was compared to the impurity thresholds of $0.3 \%$ and $0.9 \%$, respectively, which were reduced by half an order of magnitude to $0.08 \%$ and $0.4 \%$ to take into account the error margin of the model determined during the model evaluation. In the intensive farm IM, increasing herbicide efficiency from $95 \%$ in the existing system to $99 \%$ volunteer mortality does not significantly alter harvest pollution of either hybrid seed production (figure 7. A) or crop production harvests (figure 7. B). Indeed, the larger effect of competition between volunteers and cropped plants blurs the small effect of herbicide efficiency. However, the result would be very different if we were interested in controlling rapeseed volunteers in cereals. More surprisingly, an increase in seed loss before or during rape harvest because of pod shattering etc. did not modify harvest pollution of later rape crops either. Indeed, as this seed loss is the main cause of rape volunteers in fields, a greater effect would be expected. However, the time between two successive rape crops in farm IM was very long, i.e. 6 years, and the variation in seed loss were again blurred by later events. This is consistent with the results of the sensitivity analysis $[6,7]$ which shows the effect of seed loss to be significant only for the 2-3 years preceding the analysed rape crop. On farm IL, where rape was grown every three years, the increase in seed loss raised the GM content of crop production harvest by $15 \%$ compared to the $6 \%$ observed in farm IM. If the time between successive rape crops increased from 6 (existing system) to 7 years on the IM farm, the effect of seed loss was even more reduced because more seeds died. The effect was best when the 
additional crop was a spring crop where rape volunteers are rare and produce little pollen or seeds. The use of farm-saved instead of certified GM-free seeds was revealed as a very dangerous practice for harvest purity not only for the crop production fields where the farm-saved seeds were actually sown but also in the hybrid seed production field where only certified GM-free seeds were used. Indeed, the farm-saved seeds were taken from contaminated farm harvests and consequently amplified the contamination processes. The effect was much more important than for seed loss because in the latter situation the introduced GM content was only doubled whereas in the former, the content increased continuously.

The next simulations were more interesting because they concerned feasible changes in farming practices that reduced harvest contamination. The first of these was to replace the chisel plough used before rape crops by a mouldboard plough which buries recently produced volunteer seeds too deep for emergence in the rape crop. This change was indeed efficient for reducing contamination of both seed production and crop production harvests, but not below the corrected impurity thresholds. Furthermore, when the mouldboard plough was used before cereal crops, the effect was opposite, i.e. harvest pollution increased. Indeed, part of the buried seeds survive during the cereal crop and can be carried back to soil surface by tillage when a later rape crop is sown. The optimal strategy would therefore be an inverting tillage (i.e. mouldboard plough with skim-coulter) before rape crops combined with superficial tillage or a non-inverting tillage (e.g. chisel) before cereals. The latter tillage leaves the volunteer seeds to germinate during the cereal crops where the emerged seedlings can be easily eliminated by herbicides. Changes in rape sowing dates were then simulated in order to limit the length of time during which GM and non-GM varieties flower simultaneously and therefore exchange pollen. However, contamination of both seed production and crop production harvests was only decreased when the sowing of non-GM varieties was delayed. Indeed, the main effect was not related to changes in flowering dates but to volunteer emergence rates. If non-GM rape was sown later, most of the volunteers had emerged before sowing and were destroyed during seed bed preparation. In contrast, if non-GM rape was sown earlier, these volunteers emerged mostly during the non-GM crop, thus producing later partially GM pollen and seeds. Changes in sowing date are however not a very good strategy. Not only do sowing conditions deteriorate with the lateness of sowing date. Moreover, in case of hybrid seed production, changed sowing dates would disturb the flowering synchrony of male-sterile and male-fertile lines used in the hybrid seed production field. Furthermore, the effect of delaying the sowing of non-GM varieties varies considerably between fields and years and sometimes even increased harvest pollution. This was for instance the case when a set-aside was close as the delay in sowing made the flowering of the nonGM variety overlap with the volunteer flowering in the set-aside. Rapeseed volunteers do not only exist in crops but feral rape populations are frequently observed in uncultivated road-and field margins $[13,14]$. In the existing farming system, these borders were either left unmanaged or cut very early (Mid-April : onset of rape flowering) or very late (Late-June : after seed shed). If these borders were however cut each year in Mid-May, at the end of the rape flowering period, no seeds were produced and the population of next year was drastically reduced. Long-term pollen flow was thus reduced considerably, leading to a decrease in GM content in the fields. This effect was more noticeable in the case of seed production as this field was located in the part of the region where several roads (and therefore borders) were concentrated (figure 5.A). Borders are however not always cut; glyphosate is also frequently used to manage weeds and feral populations. If the transgene codes for glyphosate tolerance, such a practice is disastrous because it favours GM 
volunteers as these are glyphosate tolerant and eliminates all competing plants. Unfortunately, the borders are usually managed by public road authorities who do not choose their practices according to farmers' requests.

Rape volunteers are also frequent in set-aside, especially unsown set-aside (figure 8), even when these fields are cut in spring. The optimal strategy was to sow the set-aside fields in spring with a cover crop. In that case, most volunteers had emerged already and were destroyed at sowing. The few late-comers were then limited by competition with the cover crop. The farmer did not grow any GM varieties himself, his problems therefore originated in his neighbours' fields. To be less dependent of their practices, he could attempt to cluster his fields by exchanging fields with his neighbours. The GM content of his harvests would decrease tremendously. Unfortunately, such a scheme is not easy to achieve everywhere and requires much organisation and collaboration between farmers. Asking the neighbours not to grow rape crops next to the hybrid seed production field even during the years preceding the actual seed production was also very efficient in reducing harvest contamination and is more feasible. This change is though still a major constraint for the neighbours and difficult to carry out.

\section{Extension to other situations}

\section{Regional frequency of GM varieties}

The previous results were obtained for a given farm located in a specific farming environment. If now these conditions change, the actual values of harvest contamination also change. If, for instance the neighbours grew only $10 \%$ instead of $50 \%$ of GM rape varieties, GM content of seed production and crop production harvests decreased from $0.4 \%$ and $2 \%$ to $0.2 \%$ and $1.5 \%$, respectively. The simulated cropping systems were still ranked similarly (results not shown) but actual pollution rates were approximately $25 \%$ lower when the neighbour grew only $10 \%$ of GM rape. Late border cutting was however less efficient in reducing harvest pollution because of the lower regional GM volunteer frequency. In contrast, glyphosate treatment of borders was much more dangerous because this favouring of GM glyphosate-tolerant volunteers was more crucial, again because of the lower overall frequency. Set-aside sowing and, especially, increasing the time between two successive rape crops or clustering farm fields was much more efficient in limiting harvest pollution. Because of the lower overall GM frequency, even the longer rotation or the delay in non-GM sowing reduced the harvest contamination below the impurity threshold.

\section{Farming system}

The simulated changes in agricultural practices were less efficient in the organic medium-field farm OM (results not shown) and especially in the organic small-field farm OS (figure 9). Part of this was due to a bad collaboration with the neighbour intensive farms which were not ready to change their practices. Other practices were inefficient because of the large non-GM volunteer pressure next to the organic fields, resulting from the lower weed control. This was for instance the case of late border cutting which even increased harvest pollution slightly because it eliminated mostly non-GM volunteers of which the pollen would have diluted the GM pollen immigrating into the organic fields. Because of this high non-GM volunteer frequency, glyphosate spraying of borders was also less disastrous. 
In contrast to the intensive farm IM, the consequences of increased rape harvest loss were much more noticeable with an increase of $37 \%$ in harvest pollution when seed loss increased from 5 to $10 \%$. In the present case, the cause was not a shorter rotation than on farm IL, but rather increased proximity and sensitivity to neighbour fields previously grown with GM varieties because of the smaller fields of farm OS.

Because of the larger overall harvest pollution of organic farms and the lower efficiency of changed practices, only two techniques, i.e. spring sowing of set-aside or clustering farm fields, reduced harvest pollution below the impurity threshold. The resulting harvest contamination was however still more than ten times larger than on farm IM, partially because of the lower weed control efficiency on farm OS, but mostly because of its very small fields.

\section{Farm field size}

Again, as when comparing existing farming systems, field size was revealed as a major -factor. On the large-field intensive farm IL, the changes in farming practices had little impact (figure 10) compared to the medium-field farm IM. The cause was different from the small-field organic farm OS. In the present case, overall harvest contamination was already very low and usually below the $0.9 \%$ impurity threshold. The large fields were not very sensitive to pollen import from neighbour fields, and therefore changes in this import had little effect. Non-adequate strategies such as ploughing before cereals or advancing non-GM sowing could however make harvest contamination exceed the impurity threshold.

The effect of field size is such that even when the farming system was organic as on farm OL, harvest contamination was easily reduced below the impurity threshold (results not shown). Indeed, replacing farm-saved seeds by certified seeds was enough to assure harvest purity. In addition to the frequently efficient techniques such as sowing set-aside or clustering fields, late border cutting and delaying non-GM sowing were also sufficiently efficient.

\section{Conclusion}

The present simulations showed that when different varieties coexist, harvest contamination is inevitable, i.e. the harvest of one variety contains genes originating from the other one. The importance of this harvest contamination depends on the regional farming practices and field pattern. For these reasons, risk of gene import from neighbour farms would be greatest for smallfield organic farms. The simulations helped to identify practices that reduce GM contamination of both hybrid seed production and crop production harvests below impurity thresholds. Unfortunately, the most efficient practices were also those imposing the biggest constraints both on the farmer and on his neighbours. Furthermore, management of uncultivated areas such as road- and field margins was also shown to be crucial for harvest pollution. This was most remarkable when using glyphosate as the simulated transgene coded for glyphosate tolerance. However, volunteer management remains crucial even if the transgene codes for other characteristics, such as fatty acid content of seeds. The purity of rape harvests in case of coexisting varieties requires the collaboration of all farmers as well as other managers that operate in the concerned region.

The simulations also showed that the effects of cultivation practices and the necessary constraints to limit harvest impurities greatly varied with regional field patterns and farming practices. The present 
results can therefore not be simply extrapolated to other regions or farming systems. Each regional situation must be studied separately. This would be impossible in field trials and only be done with simulation models such as GENESYS that are fast and allow for large ranges of cropping systems and field patterns. This study is presently undertaken in several projects, both on French (Action Concertée Incitative "Impact des OGM") and European levels ("SIGMEA : Sustainable Introduction of GMOs into European Agriculture" in the Sixth Framework Programme of the European Commission). However, a model is always a simplification of reality and is therefore not always "true". The cropping systems identified as optimal in the simulations should therefore be tested in field trials or confronted to expert opinion to check their feasibility and efficiency. These cropping systems must also be evaluated for other risks, either with models or field trials, to ensure that they do not create new problems such as favouring diseases or other pests. Furthermore, the present study was limited to technical changes and their biological consequences. Before advising the use of the new cropping systems to farmers, it is necessary to perform a balanced cost and benefit analysis. Part of this was already attempted by other participants of the JRC-IPTS study [15]. Furthermore, the present study was limited to field contamination. Post-harvest contamination during transport and storage is also probable and must be evaluated [16].

\section{REFERENCES}

1. Colbach N, Clermont-Dauphin C, Meynard JM (2001). GENESYS : A model of the influence of cropping system on gene escape from herbicide tolerant rapeseed crops to rape volunteers. I. Temporal evolution of a population of rapeseed volunteers in a field. Agric Ecosyst Environ, 83 : 23553.

2. Colbach N, Clermont-Dauphin C, Meynard JM (2001). GENESYS : A model of the influence of cropping system on gene escape from herbicide tolerant rapeseed crops to rape volunteers. II. Genetic exchanges among volunteer and cropped populations in a small region. Agric Ecosyst Environ, 83 : 255-70.

3. Colbach N, Meynard JM, Clermont-Dauphin C, Champolivier J (2001). GENESYS-Colza : un modèle des effets à moyen et long terme des systèmes de culture sur les flux de gènes entre champs de colza et repousses dans un espace agricole. OCL 7 : 329-40.

4. EC (2003). Regulation (EC) $n^{\circ} 1830$ / 2003 of the European Parliament and of the Council of 22 September 2003 concerning the traceability and labelling of genetically modified organisms and the traceability of food and feed products produced from genetically modified organisms and amending Directive 200/18/EC, JOCE, L268, 10 October 2003, 24-8.

5. EC (2003). La Commission publie des recommandations visant à assurer la co-existence des cultures génétiquement modifiées et des autres cultures. IP/03/1096.

6. Colbach N, Molinari N, Clermont-Dauphin C (2004). Sensitivity analyses for a model simulating demography and genotype evolutions with time. Application to GENESYS modelling gene flow between rapeseed varieties and volunteers. Ecol Modelling (in press). 
7. Colbach N, Fargue A, Sausse C, Angevin F (2004). Evaluation and use of a spatio-temporel model of cropping system effects on gene flow. Example of the GeneSys model applied to three co-existing herbicide tolerance transgenes. Eur J Agron.

8. Champolivier J, Messéan A (1997). Impact du colza transgénique dans les systèmes de culture : étude du flux de gènes. OCL $2: 111-3$.

9. Champolivier J, Gasquez J, Messean A, Richard-Molard M (1999). Management of transgenic crops within the cropping system. In : Gene flow and agriculture : relevance for transgenic crops, PJW Lutman, ed. British Crop Protection Council 1999 Symposium Proceedings No. 72, Farnham, UK, 23340.

10. Angevin F, Colbach N, Meynard JM, Roturier C (2002). Analysis of necessary adjustments of farming practices. In : Scenarios for co-existence of genetically modified, conventional and organic crops in European agriculture. AK Bock, K Lheureux, M Libeau-Dulos, H Nilsagard, E Rodriguez-Cerezo (2002), Technical Report Series of the Joint Research Center of the European Commission, EUR $20394 \mathrm{EN}$.

11. EC (2003). Regulation (EC) N 1829 / 2003 of the European Parliament and of the Council of 22 September 2003 on genetically food and feed. Official Journal of the European Union, 18/10/2003, L268, 1-23.

12. EC (2001). Scientific Committee on Plants, opinion from 13 March 2001.

13. Crawley MJ, Hails RS, Rees M, Kohn D, Buxton J (1993). Ecology of transgenic oilseed rape in natural habitats. Nature, $363: 620-3$.

14. Pessel FD, Lecomte J, Emeriau V, Krouti M, Messéan A, Gouyon PH (2001). Persistence of oilseed rape (Brassica napus L.) outside of cultivated fields. Theor appl Genet, 102 : 841-6.

15. Bock AK, Lheureux K, Libeau-Dulos M, Nilsagard H, Rodriguez-Cerezo E (2002). Scenarios for coexistence of genetically modified, conventional and organic crops in European agriculture. Technical Report Series of the Joint Research Center of the European Commission, EUR 20394 EN.

16. Le Bail M, Meynard JM (2001). Isolement des collectes et maîtrise des disséminations au champ, Rapport du groupe 3 du programme de recherche "Pertinence économique et faisabilité d'une filière sans utilisation d'OGM". INRA - FNSEA, $56 \mathrm{p}$.

17. Mamarot J, Rodriguez A (1997). Sensibilité des mauvaises herbes aux herbicides ( $4^{\mathrm{e}}$ édition). ACTA, Paris, $319 \mathrm{p}$. 
Illustrations

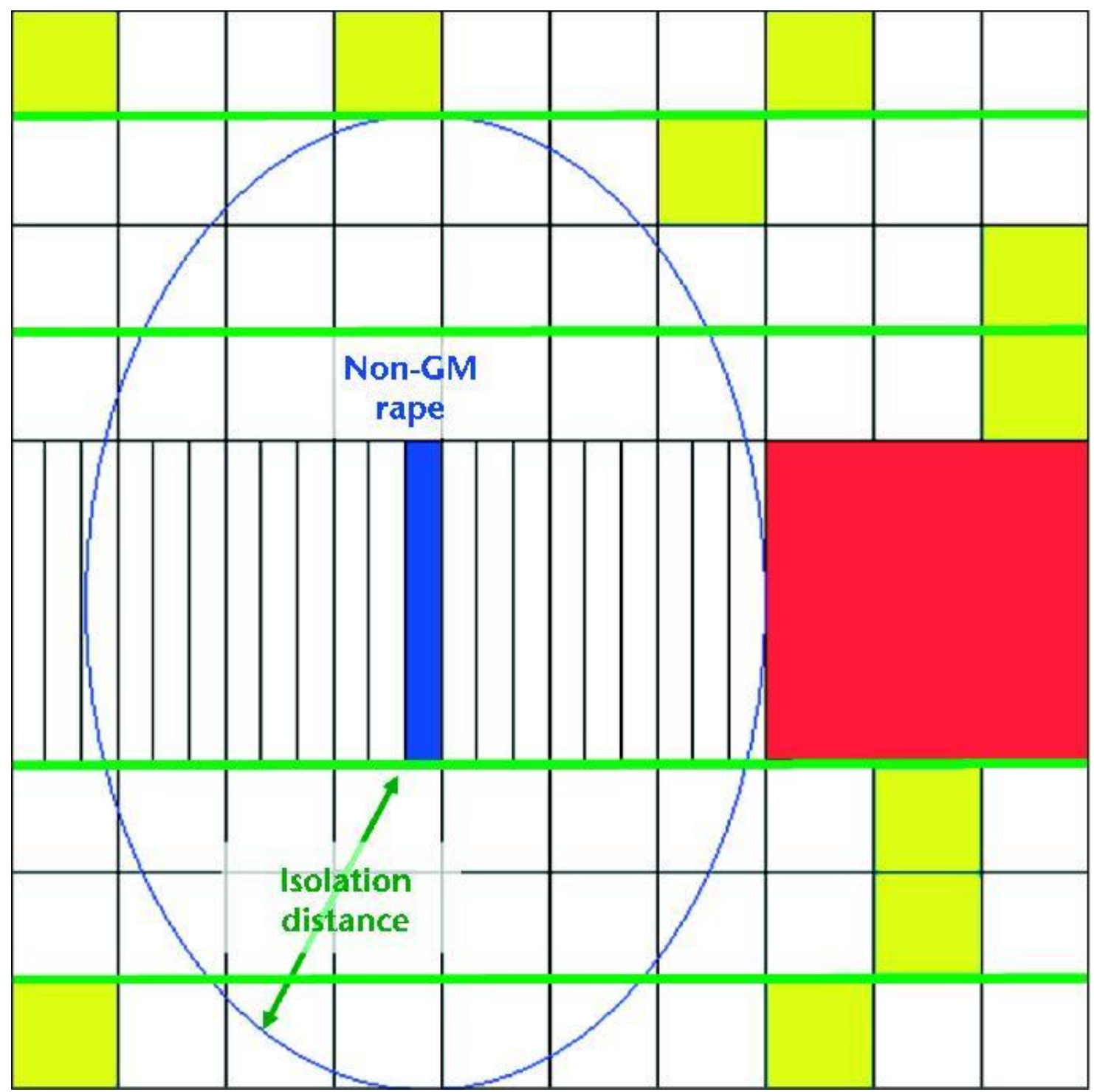

Figure 1. Example of an isolation distance of $300 \mathrm{~m}$ between a non-GM oilseed rape variety (in blue) and a GM variety (in red). All yellow fields are also grown with non-GM varieties during the same year. Green lines indicate borders. 


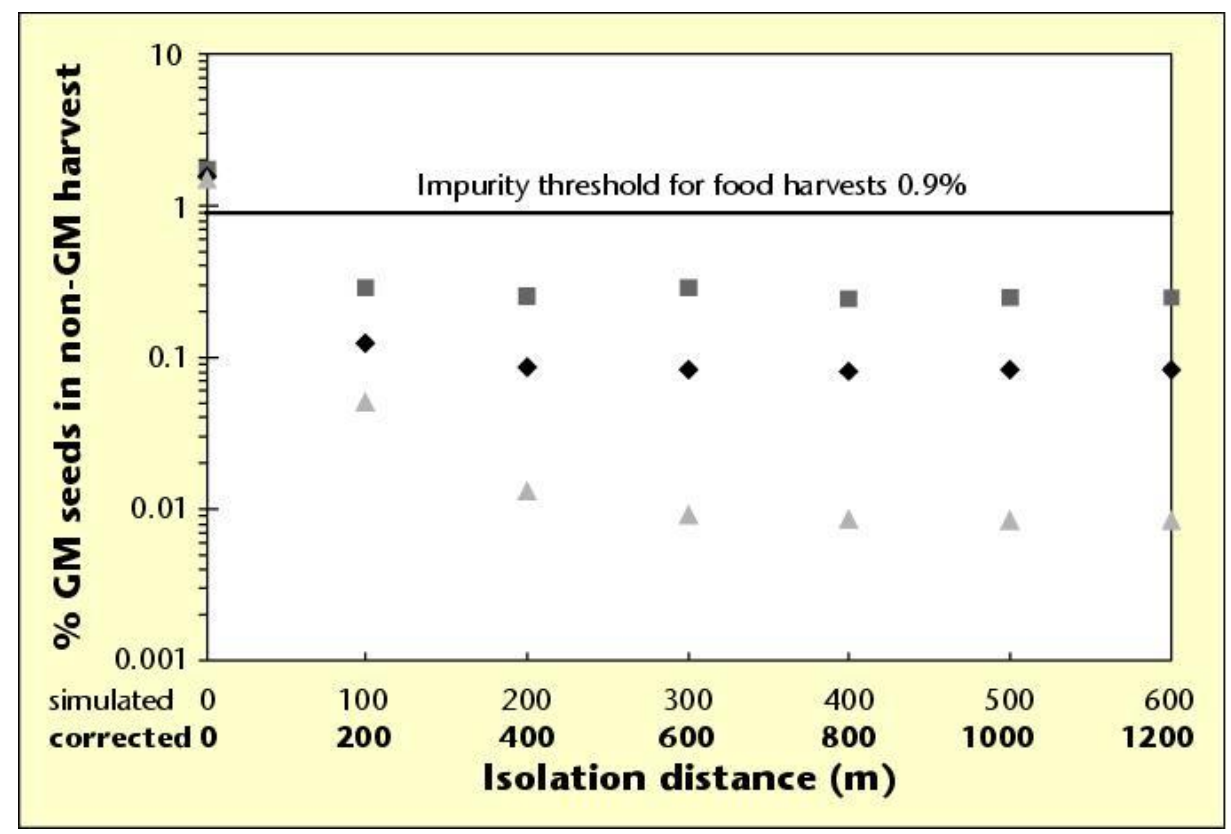

Figure 2. Effect of isolation distance between non-GM and GM varieties on harvest contamination of the non-GM rape crop 14 years after the introduction of the GM variety in a region mainly grown with non-GM varieties. Symbols indicate the GM content in the seed lots used to sow the non-GM varieties (n $0.30 \%, \mathrm{t} 0.10 \%, \mathrm{p} 0.01 \%$ ). Simulation isolation distance (first $x$ axis) was corrected for spatial underestimation (bold $x$ axis).

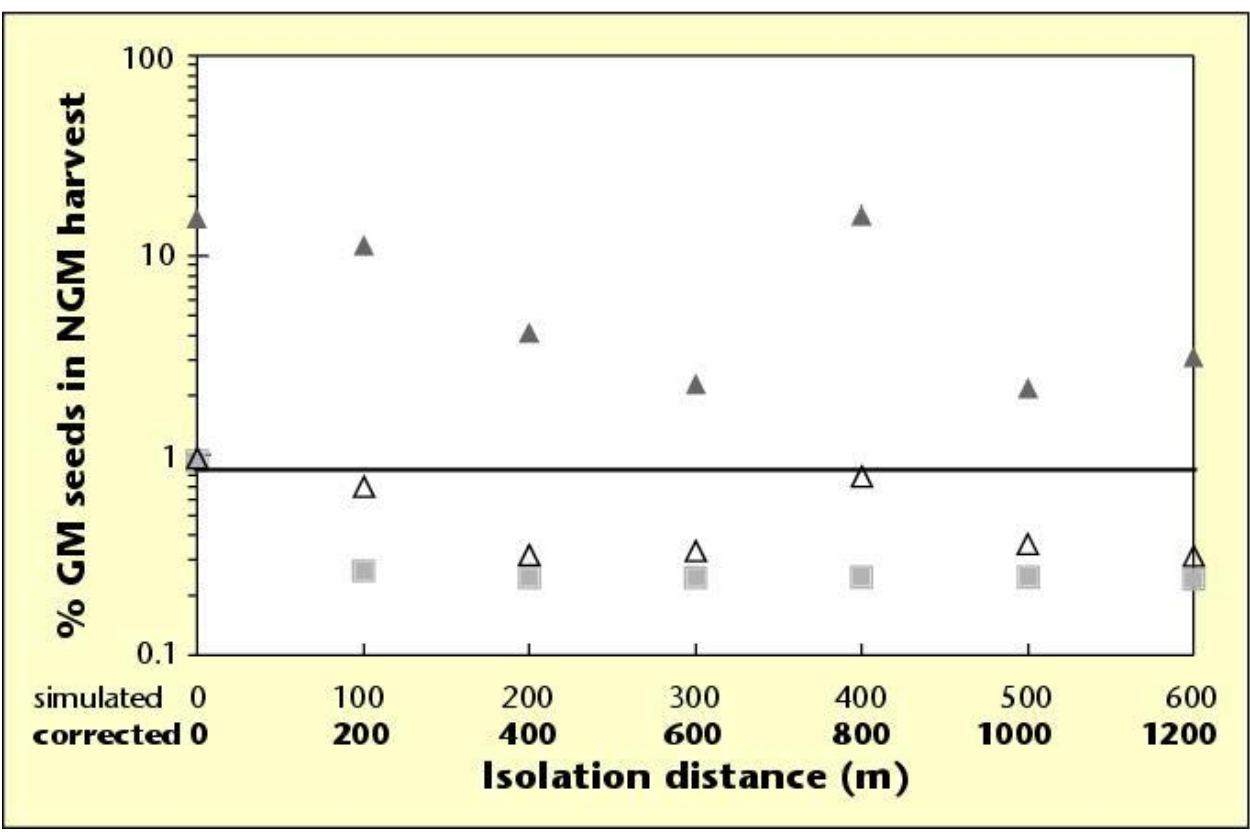

Figure 3. Effect of isolation distance on harvest pollution in a region mainly grown with GM varieties, depending on time since the introduction of GM varieties (squares : year of introduction; triangles : 14 years after introduction) and of rape volunteer management (open symbols : late cutting of borders and seta-side; closed symbols : early cutting). Simulation isolation distance (first $x$ axis) was corrected for spatial underestimation (bold $x$ axis). 


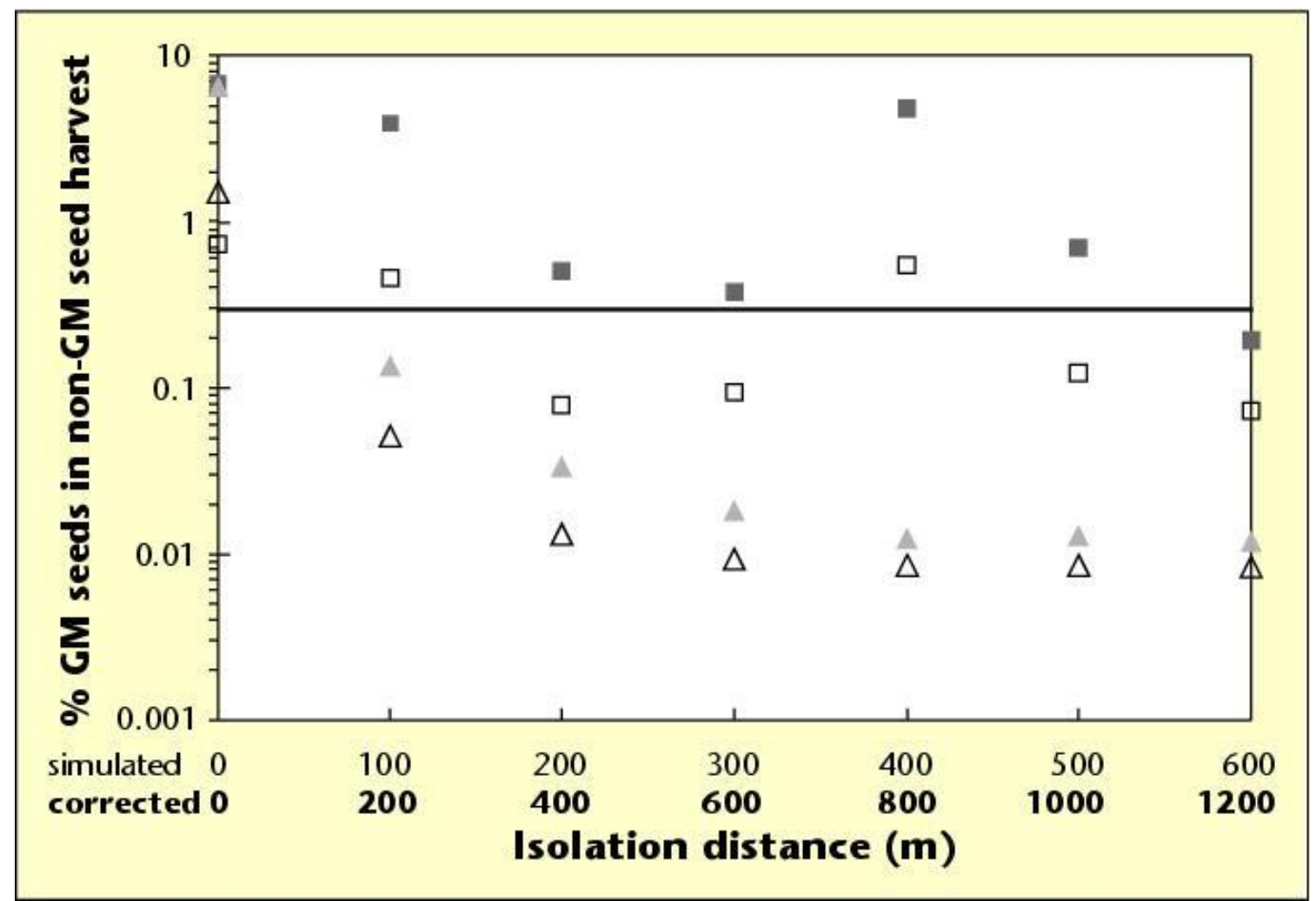

Figure 4. Effect of isolation distance on purity of seed production in a region grown with non-GM (triangles) or GM varieties (squares), depending on the type of produced seeds (conventional seed production = open symbols; hybrid seed production = closed symbols). Volunteer management of borders and set-aside was non-optimal (early cutting). Simulation isolation distance (first $x$ axis) was corrected for spatial underestimation (bold $x$ axis). 


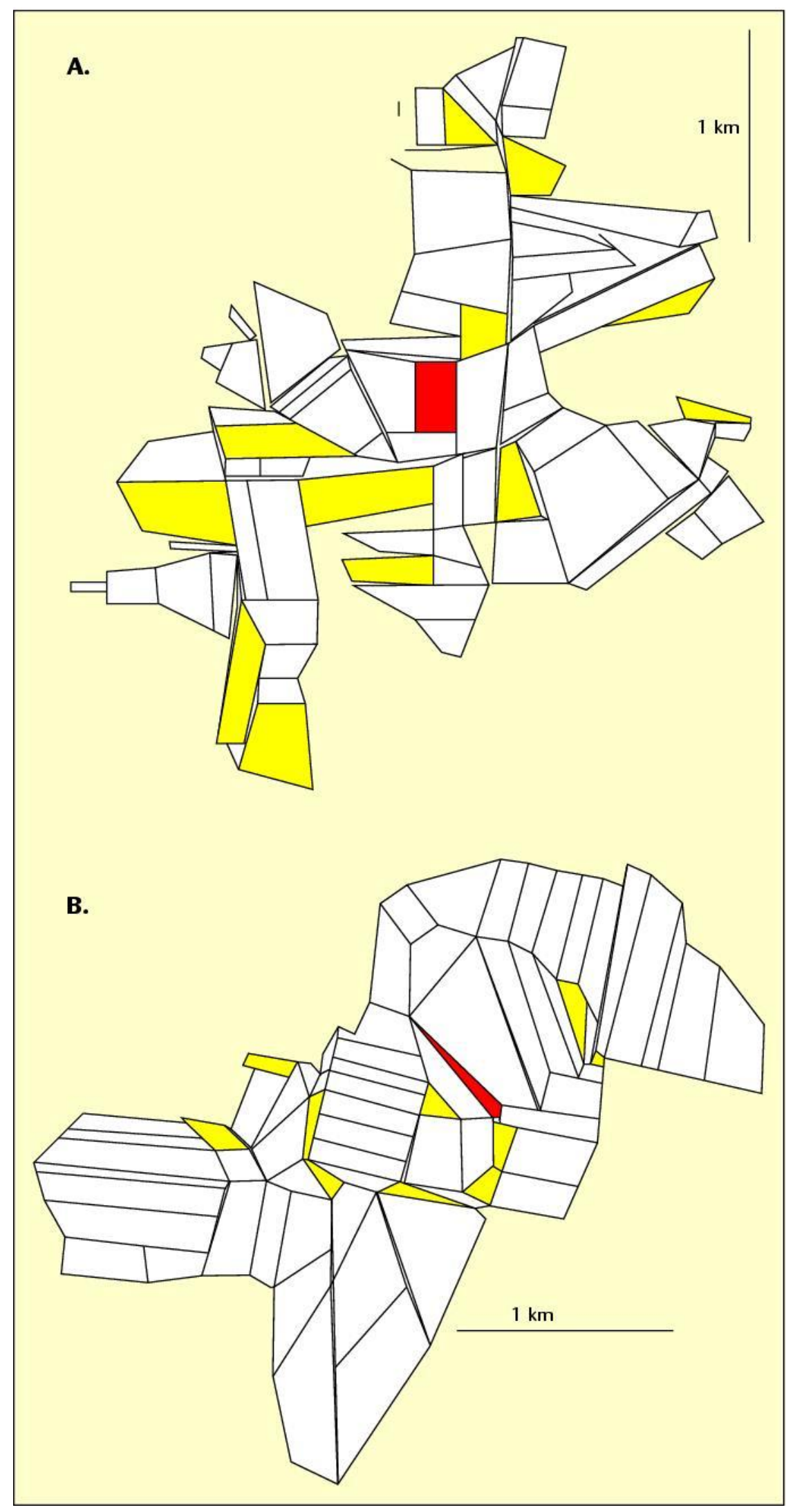

Figure 5. Field plans of medium-field ( $A$ : IM and OM) and small-field farms ( $B: O S)$ used for evaluating and designing cropping systems. Coloured fields belong to the farm, the red field was used for hybrid seed production every 6 years. 


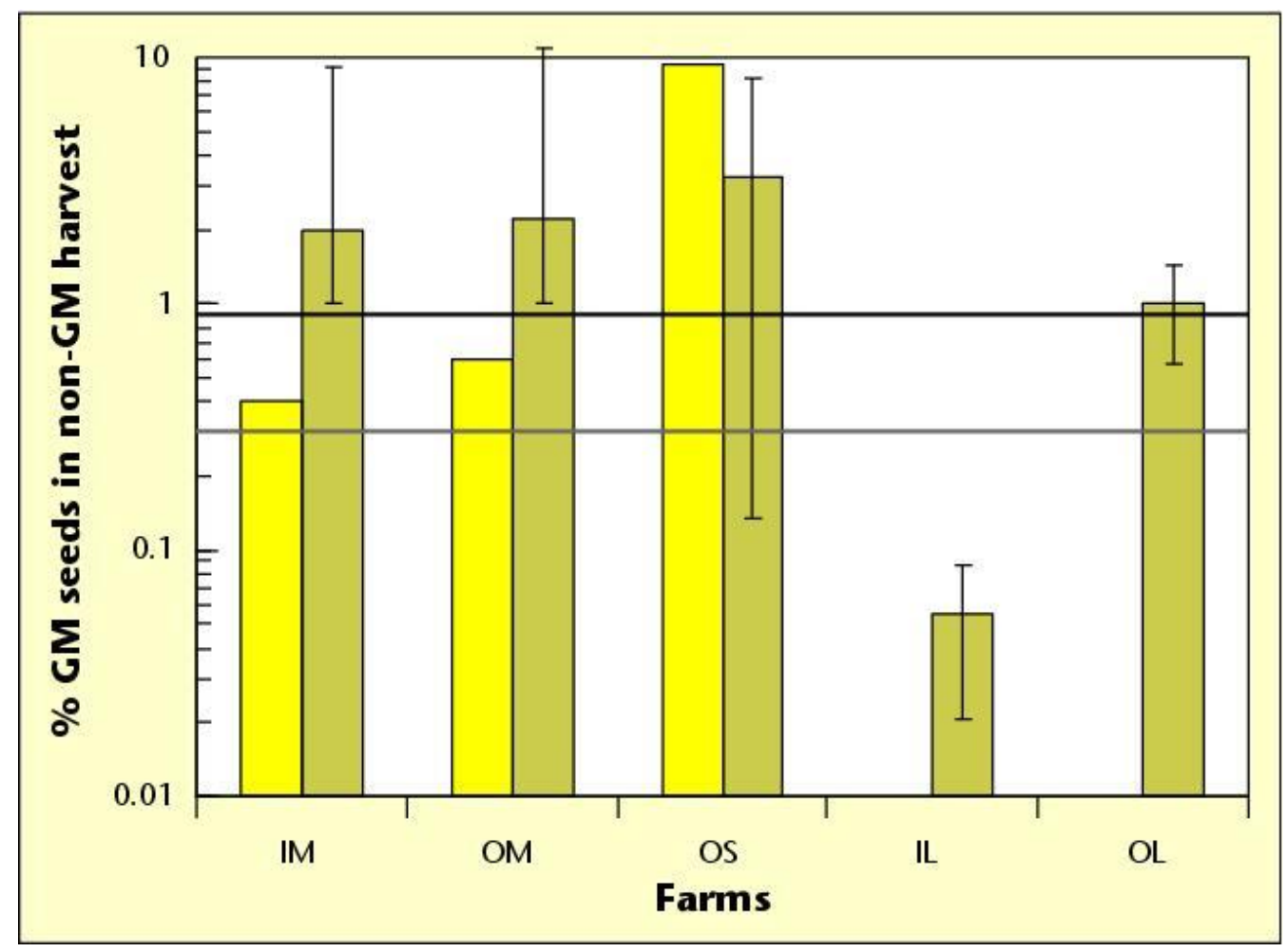

Figure 6. Impurity rates in crop production (blue bars, mean of all farm fields for years 7 to 14 after GM introduction) and hybrid seed production harvests (red bars, year 14) for the five simulated farms. Error bars indicate minimum and maximum values of all farm fields for years 7 to 14 after GM introduction. 


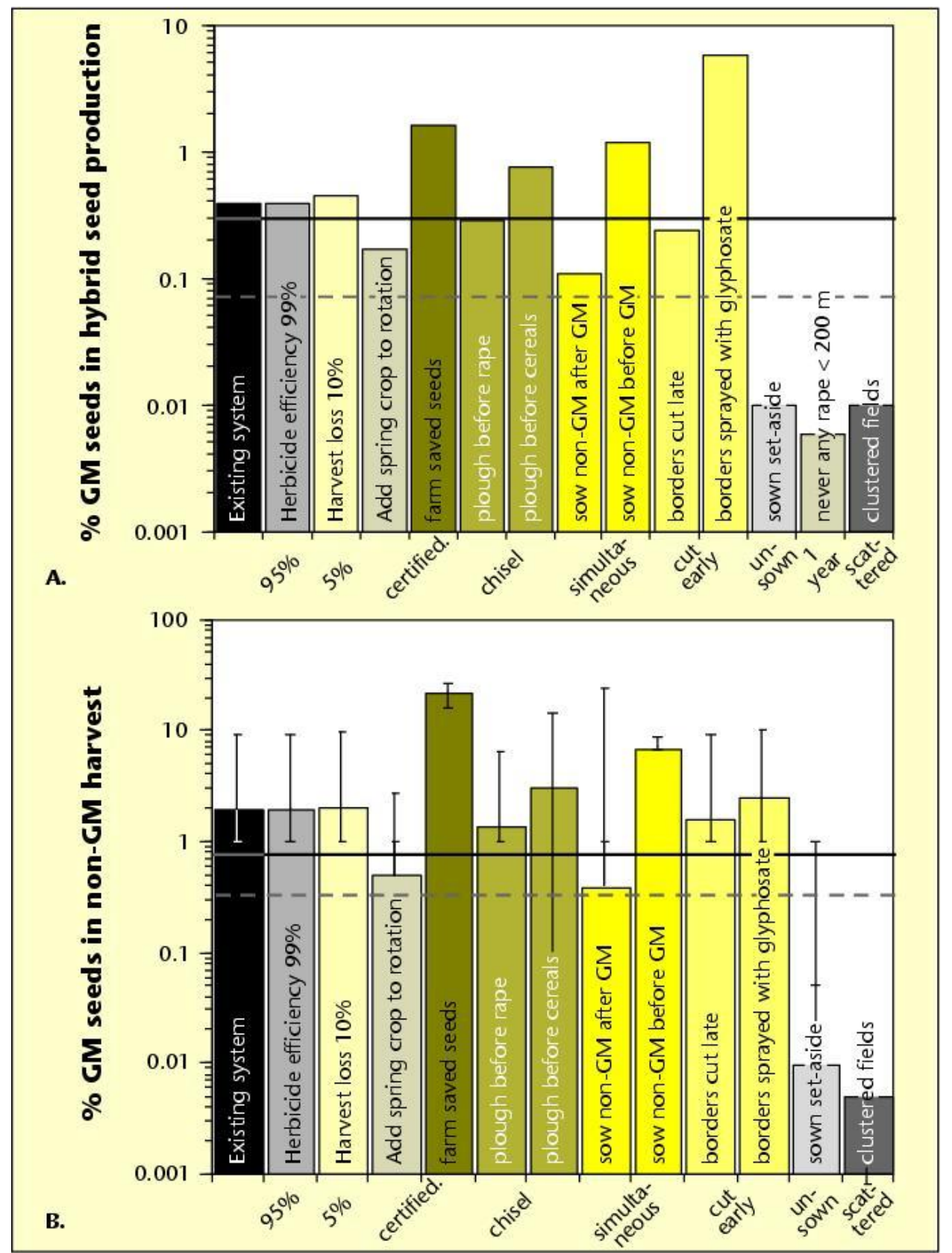

Figure 7. Effect of changes in farming practices (indicated on bars) on the GM content of hybrid seed production (A) and crop production harvests (B) of oilseed rape in the medium-field intensive farm IM. Comparison to existing system (legend of $x$ axis) and impurity threshold (-- absolute value ; - - corrected for model underestimation). Error bars indicate minimum and maximum values of all fields and years (from 7 to 13 years after the introduction of GM varieties). 


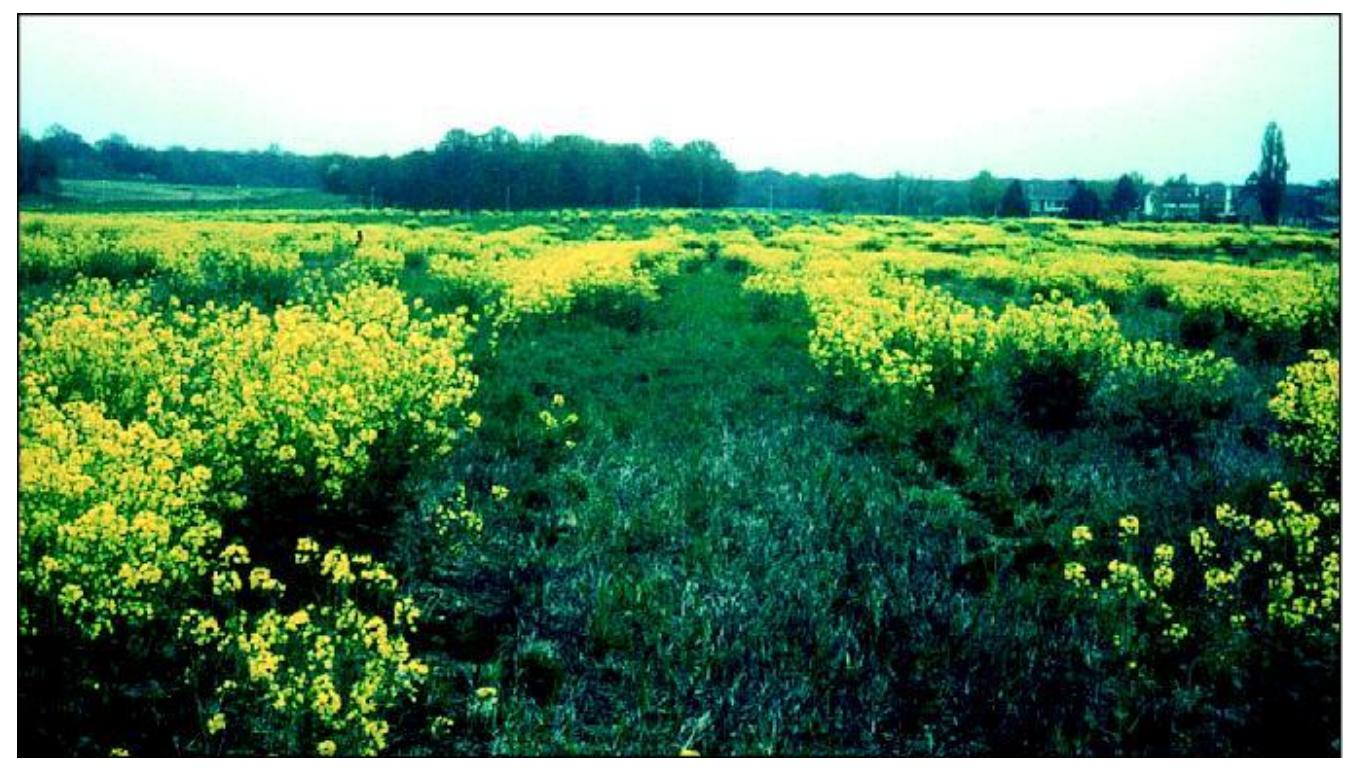

Figure 8. Rapeseed volunteers in unsown set-aside (Yvelines, April 1995).

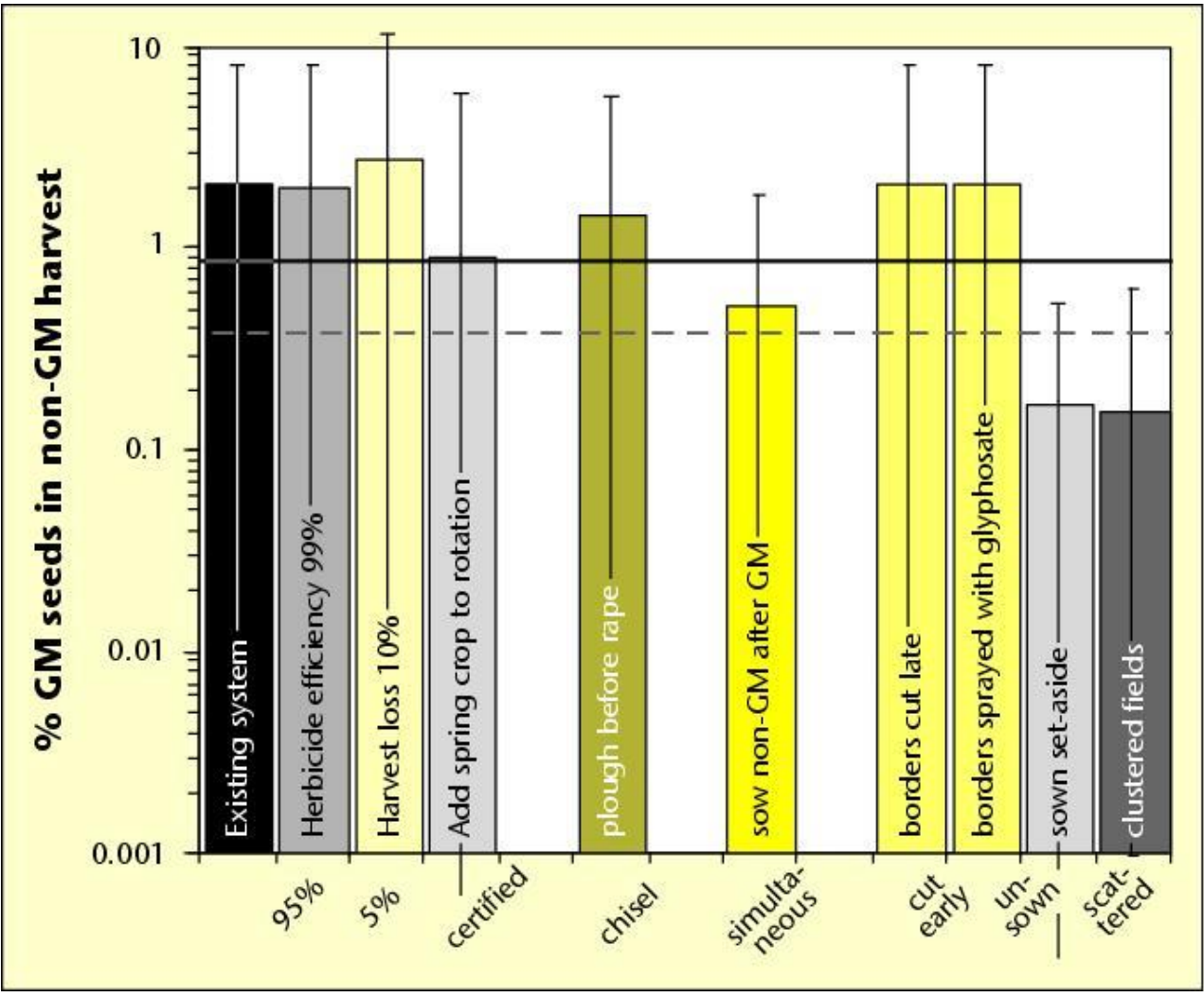

Figure 9. Effect of changes in farming practices (indicated on bars) on the GM content of crop production harvests of oilseed rape in the small-field organic farm OS. Comparison to existing system (legend of $x$ axis) and impurity threshold (-- absolute value ; -- - corrected for model underestimation). Error bars indicate minimum and maximum values of all fields and years (from 7 to 13 years after the introduction of GM varieties). 


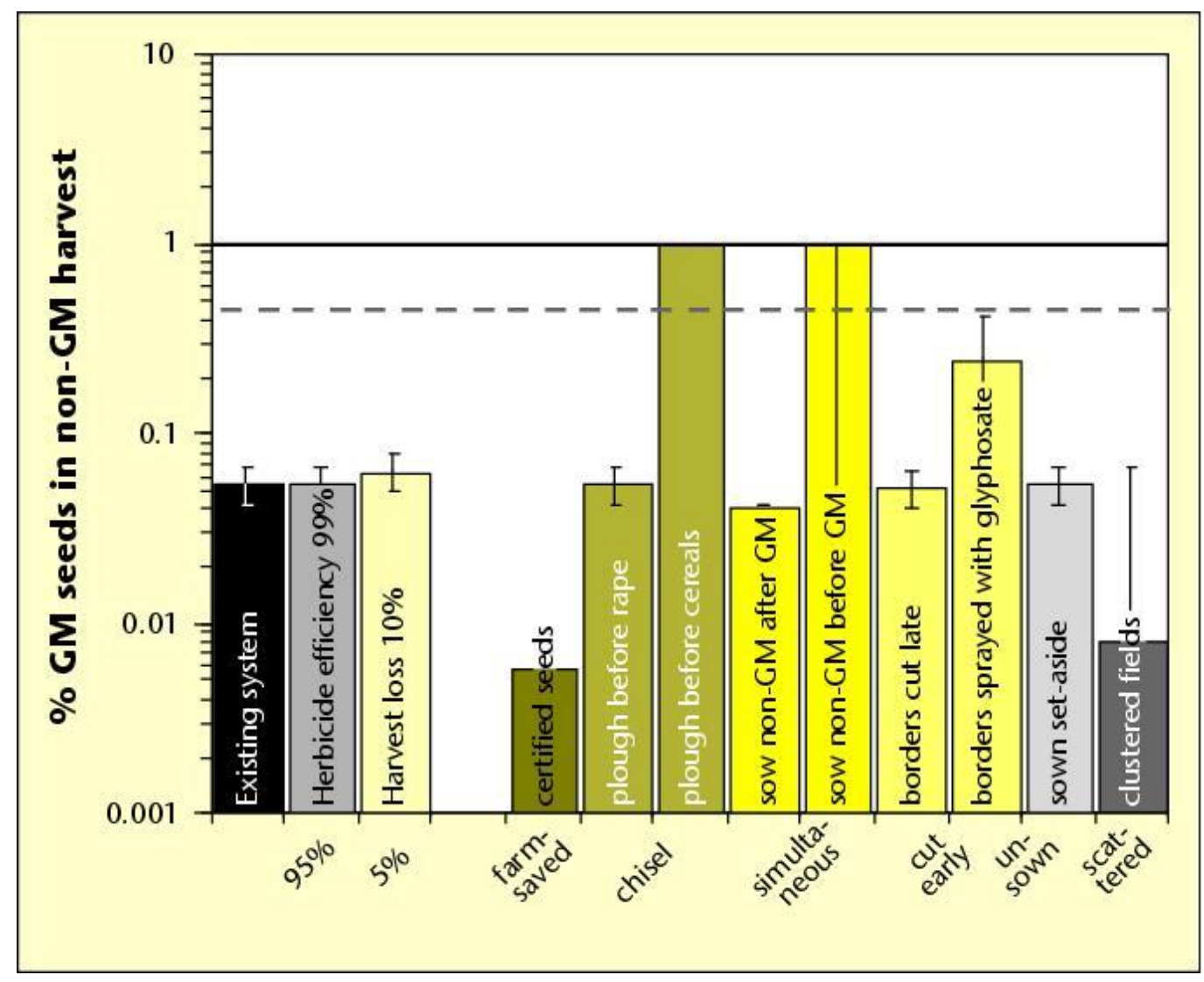

Figure 10. Effect of changes in farming practices (indicated on bars) on the GM content of crop production harvests of oilseed rape in the large-field intensive farm IL. Comparison to existing system (legend of $x$ axis) and impurity threshold (-- absolute value ; -- - corrected for model underestimation). Error bars indicate minimum and maximum values of all fields and years (from 7 to 13 years after the introduction of GM varieties). 